\title{
Systematic review and meta-analysis: bezafibrate in patients with primary biliary cirrhosis
}

\author{
This article was published in the following Dove Press journal: \\ Drug Design, Development and Therapy \\ 30 September 2015 \\ Number of times this article has been viewed
}

\author{
Qin Yin, ${ }^{1,2, *}$ Jingjing $\mathrm{Li},{ }^{3, *}$ \\ Yujing $\mathrm{Xia},{ }^{3}$ Rong Zhang, ${ }^{3,4}$ \\ Jianrong Wang, ${ }^{3,4}$ Wenxia \\ Lu, ${ }^{3,4}$ Yuqing Zhou, ${ }^{1,2}$ \\ Yuanyuan Zheng, ${ }^{3}$ \\ Huerxidan Abudumijiti, ${ }^{3}$ \\ Rongxia Chen, ${ }^{3}$ Kan Chen, ${ }^{3}$ \\ Sainan $\mathrm{Li}^{3}{ }^{3}$ Tong Liu, ${ }^{3}$ Fan \\ Wang, ${ }^{3}$ Jie Lu, ${ }^{3}$ Yingqun \\ Zhou, ${ }^{3}$ Chuanyong Guo ${ }^{3}$ \\ 'Department of Gastroenterology, \\ Shanghai Tenth People's Hospital, \\ Tongji University School of Medicine, \\ Shanghai, ${ }^{2}$ The First Affiliated Hospital \\ of Soochow University, Suzhou, \\ ${ }^{3}$ Department of Gastroenterology, \\ Shanghai Tenth People's Hospital, \\ Tongji University School of Medicine, \\ Shanghai, ${ }^{4}$ The First Clinical Medical \\ College of Nanjing Medical University, \\ Nanjing, People's Republic of China \\ *These authors contributed \\ equally to this work and should be \\ considered co-first authors
}

Background and aim: Ursodeoxycholic acid (UDCA) is the standard treatment for primary biliary cirrhosis (PBC), but not all cases respond well. Evidence has shown that combination therapy of UDCA with bezafibrate significantly improved liver function. A meta-analysis was performed to assess the efficacy and safety of UDCA and bezafibrate combination therapy in the treatment of PBC.

Results: Nine trials, with a total of 269 patients, were included in the analysis. The bias risk of these trials was high. Compared with UDCA alone, the combination with bezafibrate improved the Mayo risk score (mean difference [MD], 0.60; 95\% confidence interval [CI], 0.25-0.95; $P=0.0008)$ and liver biochemistry: alkaline phosphatase (MD, $-238.21 \mathrm{IU} / \mathrm{L} ; 95 \% \mathrm{CI},-280.83$ to $-195.60 ; P<0.00001$ ); gamma-glutamyltransferase (MD, $-38.23 \mathrm{IU} / \mathrm{L} ; 95 \% \mathrm{CI},-50.16$ to $-25.85 ; P<0.00001)$; immunoglobulin $\mathrm{M}(\mathrm{MD},-128.63 \mathrm{IU} / \mathrm{L} ; 95 \% \mathrm{CI},-151.55$ to -105.71 ; $P<0.00001$ ); bilirubin (MD, $-0.20 \mathrm{mg} / \mathrm{dL} ; 95 \% \mathrm{CI},-0.33$ to $-0.07 ; P=0.002$ ); triglycerides (MD, $-26.84 \mathrm{mg} / \mathrm{dL} ; 95 \% \mathrm{CI},-36.51$ to $-17.17 ; P<0.0001)$; total cholesterol (MD, $-21.58 \mathrm{mg} / \mathrm{dL}$; $95 \% \mathrm{CI},-30.81$ to $-12.34 ; P<0.0001)$, and serum alanine aminotransferase (MD, $-10.24 \mathrm{IU} / \mathrm{L}$; $95 \% \mathrm{CI},-12.65$ to $-78.5 ; P<0.00001)$. However, combination therapy showed no significant differences in the incidence of all-cause mortality or pruritus, and may have resulted in more adverse events (risk ratio [RR], 0.22; 95\% CI, 0.07-0.67; $P=0.008$ ).

Conclusion: Combination therapy improved liver biochemistry and the prognosis of $\mathrm{PBC}$, but did not improve clinical symptoms or incidence of death. Attention should be paid to adverse events when using bezafibrate.

Keywords: bezafibrate, meta-analysis, primary biliary cirrhosis, ursodeoxycholic acid

\section{Introduction}

Primary biliary cirrhosis (PBC) is a chronic progressive inflammatory autoimmunemediated cholestatic disease. Ninety percent of patients with PBC are females and most are diagnosed after the age of 40 years. It is characterized by the destruction of bile ducts and nonsuppurative inflammation, and subsequent development of liver fibrosis and cirrhosis, eventually leading to liver failure. ${ }^{1,2}$ Patients with PBC have been treated with many drugs. Ursodeoxycholic acid (UDCA), a bile acid, is the most extensively used drug in these patients. However, some patients respond poorly, and we were unable to demonstrate any significant effect of UDCA on all-cause mortality or liver transplantation, pruritus, or fatigue in patients with PBC. ${ }^{2}$ Over the years, a number of other drugs have been tried for the treatment of PBC, including immunomodulatory drugs, ${ }^{3-7}$ corticosteroids, ${ }^{8}$ budesonide,,${ }^{9}$ and fibrates. ${ }^{10}$ Immunomodulatory drugs, such as azathioprine, prednisolone, cyclosporine, D-penicillamine, methotrexate, or colchicine, did not lead to widespread acceptance of these drugs for PBC patients and were associated with a number of adverse events. The use of corticosteroids to suppress the inflammation in PBC has always been considered as a very attractive approach, 
but corticosteroids cannot improve the clinical symptoms as well as the mortality.

Bezafibrate was originally developed as a drug for treatment of hyperlipidemia and used for the prevention of cardiovascular diseases. Bezafibrate decreases serum hepatobiliary enzyme activity even in normal subjects, and this used to be considered as a side effect. Recently, this drug has come to be recognized as a potential anticholestatic medicine for the treatment of PBC that does not respond sufficiently to UDCA monotherapy. The mechanism by which bezafibrate improves cholestasis, cytolysis, and modifies the immune response in patients with $\mathrm{PBC}$ are not known. A recent study elucidated that bezafibrate inhibits hepatic synthesis and the uptake of bile acids, enhances bile-acid detoxification, and stimulates canalicular MDR3, MDR1, and MRP2 activities as a dual peroxisome proliferator-activated receptors/PXR agonist. ${ }^{11}$ And most of the people agree that bezafibrate induces multidrug resistant-3 gene expression and upregulates P-glycoprotein expression, thus facilitating the production of biliary phospholipids. This results in a reduction in the cytotoxic effects of these phospholipids on the biliary epithelia. ${ }^{12}$ We therefore performed a meta-analysis to assess the effects of bezafibrate in $\mathrm{PBC}$.

\section{Materials and methods Search strategy}

All the studies were identified and selected by searching PubMed, the Cochrane Library, the Chinese Biomedical Database, EMBASE, and Medline (updated to April 2015) using the search terms "ursodeoxycholic acid", "bezafibrate", "PBC", and "randomized controlled trial". A manual search of all review articles, conference literature, retrieved original studies, and abstracts was conducted. Principal authors were contacted to obtain missing information and additional published or unpublished trials.

\section{Inclusion criteria}

Randomized clinical trials assessing bezafibrate in patients with PBC, irrespective of blinding, language, publication year, or publication status, were included. For crossover trials, only data from the first period were used. Self-control clinical trials were also included in this study. For assessment of adverse events, quasi-randomized and observational studies were also considered, but we did not perform specific searches for these studies. All the study protocol complies with good clinical practice according to the Declaration of Helsinki and was approved by the Institutional Ethics Committee.

\section{Data extraction}

Two of the authors (Qin Yin and Jingjing Li) independently scrutinized all articles, and any disagreement was resolved by consensus. The following data were extracted from each included study: name of the first author, year of publication, daily dose of oral therapy, number of patients, duration of treatment, Mayo risk score, liver biochemistry, symptoms, death, and adverse events.

\section{Data analysis}

The meta-analysis was performed using RevMan 5.2 software (The Nordic Cochrane Center, The Cochrane Collaboration, Oxford, UK). For dichotomous outcomes, we calculated the risk ratio (RR), and for continuous outcomes, the mean difference (MD), all with 95\% confidence intervals (CIs). To calculate the MDs, we combined data reported as change from baseline values with final measurement values in the meta-analysis using the MD method in RevMan. We tested heterogeneity using the $\chi^{2}$ and $I^{2}$ tests, and a $P$-value $<0.10$ or an $I^{2}$-value $>50 \%$ was considered to indicate substantial heterogeneity. Meta-analysis of the data was performed with both a random-effects model and a fixed-effects model to ensure robustness of the results. A fixed-effects model was used when the heterogeneity test showed $P>0.10$ and $I^{2}<50 \%$; if $I^{2}>50 \%$ in the subgroup, a random-effects model was used. We did not perform a funnel plot, as there were only nine trials in this meta-analysis.

We performed subgroup analyses, in which trials were grouped according to the duration of treatment and severity of adverse events.

\section{Methodological quality of the included studies}

We assessed the methodological quality of the randomized clinical trials using six components: allocation sequence generation, allocation concealment, blinding, incomplete outcome data, selective outcome reporting, and other potential sources of bias (Table 1). ${ }^{12}$ The nine included trials were evaluated according to the parameters mentioned in Table 1 and are summarized in Figure 1. Risk of bias was assessed according to seven components: allocation sequence generation, allocation concealment, blinding of participants and personnel, blinding of outcome assessment, handling of incomplete outcome data, selective outcome reporting, and other potential sources of bias. All the nine included trials were assessed as having high risk of bias; therefore, our statistical analyses are based only on trials with high risk of bias (Figure 2). 
Table I Criteria used to assess risk of bias in included studies

Trials assessed as having "low risk of bias" in all the specified individual domains were considered "trials with low risk of bias". Trials assessed as having "uncertain risk of bias" or "high risk of bias" in one or more of the specified individual domains were considered "trials with high risk of bias". Allocation sequence generation

Low risk of bias: sequence generation was achieved using computer random number generation or a random number table. Drawing lots, tossing a coin, shuffling cards and throwing dice are adequate if performed by an independent adjudicator.

Unclear risk of bias: the trial is described as randomized, but the method of sequence generation was not specified.

High risk of bias: the sequence generation method is not, or may not be, random. Quasi-randomized studies, those using dates, names or admittance numbers in order to allocate patients are inadequate and will be excluded for the assessment of benefits, but not for harms.

\section{Allocation concealment}

Low risk of bias: allocation was controlled by a central and independent randomization unit, sequentially numbered, opaque and sealed envelopes or similar, so that intervention allocations could not have been foreseen in advance of, or during, enrolment.

Unclear risk of bias: the trial was described as randomized, but the method used to conceal the allocation was not described, so that intervention allocations might have been foreseen in advance of, or during, enrolment.

High risk of bias: if the allocation sequence was known to the investigators who assigned patients or if the study was quasi-randomized. Quasirandomized studies will be excluded for the assessment of benefits, but not for harms.

\section{Blinding}

Low risk of bias: the trial was described as blinded, the parties that were blinded, and the method of blinding was described, so that knowledge of allocation was adequately prevented during the trial.

Unclear risk of bias: the trial was described as blind, but the method of blinding was not described, so that knowledge of allocation was possible

during the trial.

High risk of bias, the trial was not blinded, so that the allocation was known during the trial.

Incomplete outcome data

Low risk of bias: the numbers and reasons for dropouts and withdrawals in all intervention groups were described or if it was specified that there were no dropouts or withdrawals.

Unclear risk of bias: the report gave the impression that there had been no dropouts or withdrawals, but this was not specifically stated.

High risk of bias: the number or reasons for dropouts and withdrawals were not described.

Selective outcome reporting

Low risk of bias: pre-defined, or clinically relevant and reasonably expected outcomes are reported on.

Unclear risk of bias: not all pre-defined, or clinically relevant and reasonably expected outcomes are reported on or are not reported fully, or it is unclear whether data on these outcomes were recorded or not.

High risk of bias: one or more clinically relevant and reasonably expected outcomes were not reported on; data on these outcomes were likely to have been recorded.

\section{Other bias}

Low risk of bias: the trial appears to be free of other components that could increase risk of bias.

Unclear risk of bias: the trial may or may not be free of other components that could increase risk of bias.

High risk of bias: there are other factors in the trial that could increase risk of bias (eg, for-profit involvement, authors have conducted trials on the same topic).

We did not perform a funnel plot because we did not have the recommended minimal number of ten or more trials in any meta-analysis.

\section{Results}

From 147 trials, ${ }^{11,13-20}$ nine were selected for the analysis (Figure 3). These studies involved 269 patients: 144 were randomized to the UDCA monotherapy group and 125 to the combination therapy (UDCA and bezafibrate) group. The baseline characteristics of the nine trials are listed in Table 2 . The mean age was 54-64 years and the mean follow-up interval was 3-96 months. The daily doses of UDCA were $600-1,500 \mathrm{mg} /$ day, and the daily dose of bezafibrate was $400 \mathrm{mg} /$ day. Eight trials were published as full text articles and one trial as an abstract and letter to the editor. The descriptive results are shown in Table 3.

\section{Meta-analysis}

1. Mortality: nine trials, which included 269 patients, reported data regarding this end point. One of 144 patients in the monotherapy groups and three of 125 patients in the combination therapy groups died..$^{11,13-20}$ There was medium heterogeneity $\left(P=0.20, I^{2}=38 \%\right)$ and there were no significant differences between the groups (RR, 0.41 ; 95\% CI, 0.07-2.29; $P=0.31$; Figure 4).

2. Pruritus: four trials, which included 131 patients, reported data regarding this end point. Symptoms improved in 22 of 68 patients in the monotherapy groups and in 12 of 63 patients in the combination therapy groups. ${ }^{14,17-19}$ There was medium heterogeneity $\left(P=0.09, I^{2}=54 \%\right)$ and no significant differences between the groups (RR, 1.60; 95\% CI, 0.90-2.85; $P=0.11$; Figure 5).

3. Adverse events: nine trials provided information on adverse events and could be included in the analyses. 


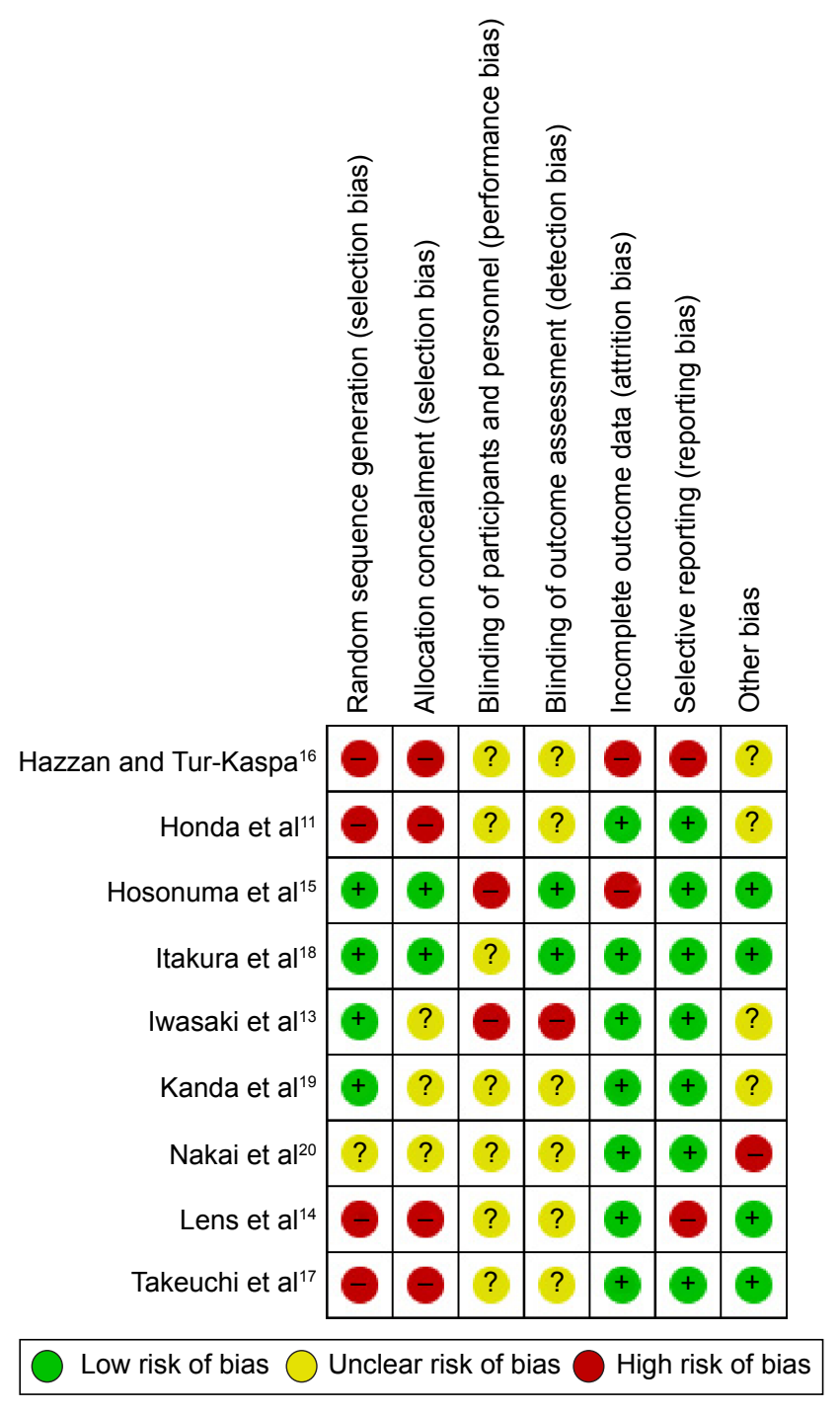

Figure I Risk of bias in included studies.

Notes: + , indicates an increase, - , indicates a decrease and ?, indicates this is unclear.

The included trials reported 15 of 352 patients having adverse events. The incidence of adverse events was one of 186 patients in the monotherapy groups versus 14 of 166 patients in the combination therapy groups. ${ }^{11,13-20}$
Meta-analyses showed that combination therapy may cause more adverse events (RR, 0.22; 95\% CI, 0.07-0.67; $P=0.008$; Figure 6).

The subgroup analyses, stratifying the trials according to the severity of the adverse events, did not reveal significant differences (Figure 6). Heterogeneity was absent $\left(P=0.83, P^{2}=0 \%\right.$ ).

4. Mayo risk score: two trials, which included 60 patients, reported data regarding this end point. ${ }^{15,17}$ Combination therapy significantly decreased the Mayo risk score compared with UDCA monotherapy (MD, 0.60; 95\% $\mathrm{CI}, 0.25-0.95 ; P=0.0008$; Figure 7). This suggests that addition of bezafibrate to UDCA may improve the prognosis of PBC. There was low heterogeneity $(P=0.24$, $r^{2}=26 \%$ ).

5. Alkaline phosphatase (ALP): nine trials, which included 247 patients, reported data regarding this end point. ${ }^{11,13-20}$ Combination therapy with UDCA and bezafibrate was more effective than UDCA monotherapy in decreasing the serum ALP (MD, $-238.21 \mathrm{IU} / \mathrm{L} ; 95 \% \mathrm{CI},-280.83$ to $-195.60 ; P<0.00001$; Figure 8 ).

The subgroup analyses, stratifying the trials according to the duration of treatment, did not reveal significant differences (Figure 8). There was substantial heterogeneity $\left(P=0.0003, P^{2}=65 \%\right)$.

6. Gamma-glutamyltransferase: seven trials, which included 194 patients, reported data regarding this end point. ${ }^{11,13,14,16,18-20}$ Combination therapy with UDCA and bezafibrate was more effective than UDCA monotherapy in decreasing gamma-glutamyltransferase (MD, -38.23 IU/L; 95\% CI, -50.16 to $-25.85 ; P<0.00001$; Figure 9). In the subgroup counting change from the baseline, there were no significant differences between the groups (MD, $-15.47 \mathrm{IU} / \mathrm{L} ; 95 \% \mathrm{CI},-32.11$ to $1.18 ; P=0.07 ; P^{2}=44 \%$ ). However, in the subgroup counting final measurement values, there were significant differences between the groups

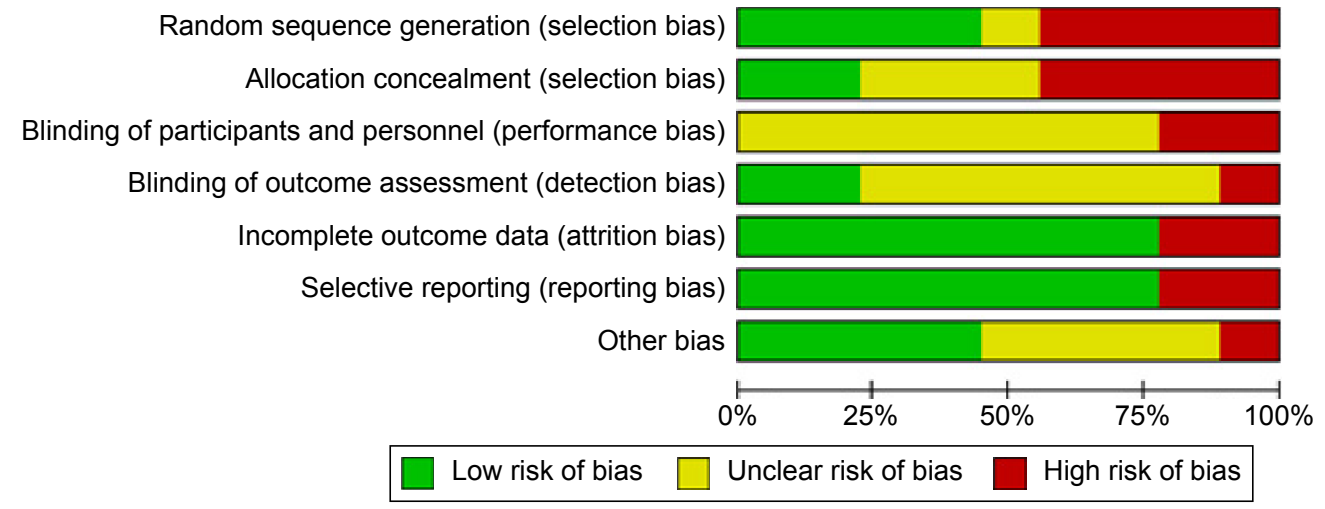

Figure 3 Risk of bias graph: review of authors' judgments regarding each risk of bias item presented as percentages across all included studies. 


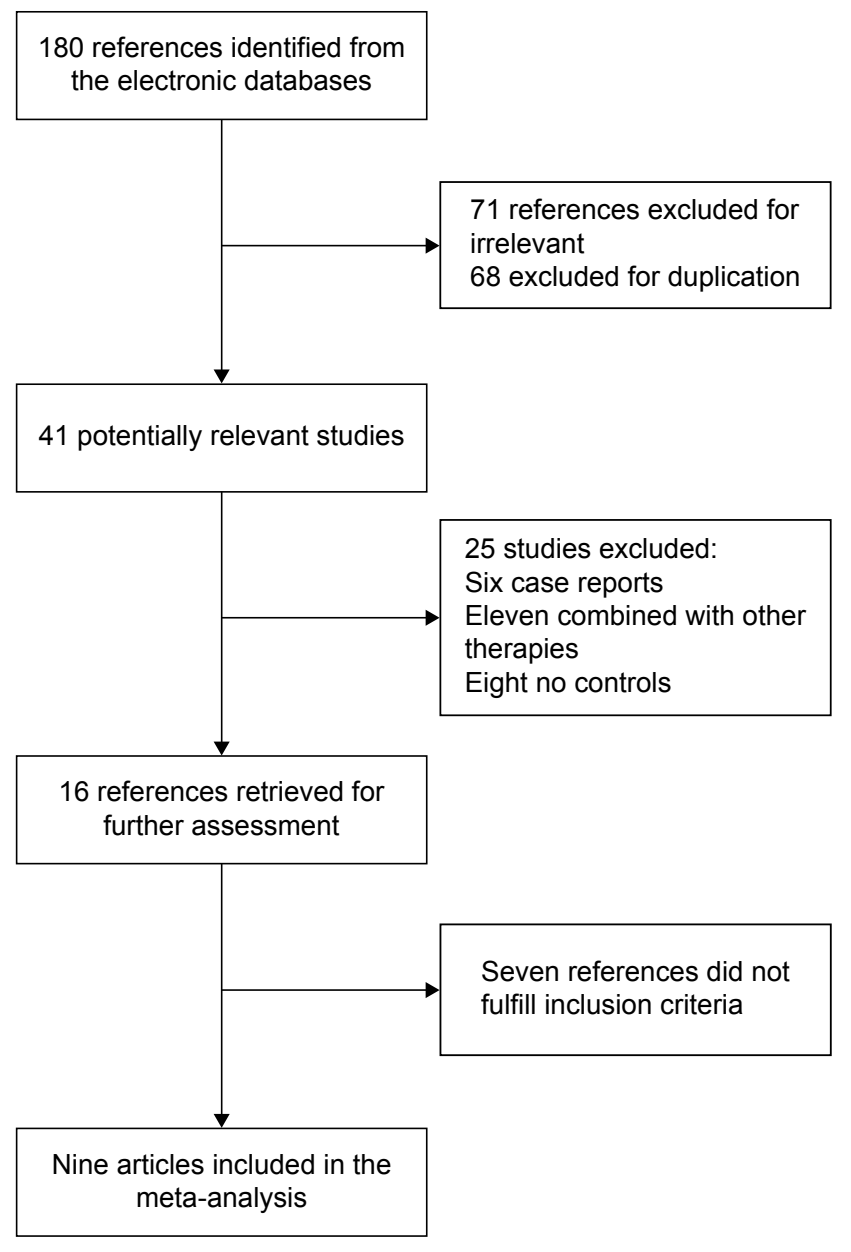

Figure 3 Flow diagram of trial selection.

(MD, $-66.41 \mathrm{IU} / \mathrm{L} ; 95 \% \mathrm{CI},-84.93$ to $-47.88 ; P<0.0001$; $\left.I^{2}=0 \%\right)$. There was no significant heterogeneity in each subgroup.

7. Alanine aminotransferase (ALT): four trials, which included 112 patients, reported data regarding this end point. ${ }^{13,14,17,18}$ Combination therapy with UDCA and bezafibrate was more effective than UDCA monotherapy in decreasing the serum ALT (MD, -10.24 IU/L; 95\% CI, -12.65 to $-78.5 ; P<0.00001$; Figure 10$)$.

The subgroup analyses, stratifying the trials according to the duration of treatment, did not reveal significant differences (Figure 10). There was no significant heterogeneity $\left(P=0.16, I^{2}=42 \%\right)$.

8. Immunoglobulin M: six trials, which included 199 patients, reported data regarding this end point. ${ }^{11,13,17-20}$ Combination therapy with UDCA and bezafibrate was more effective than UDCA monotherapy in decreasing immunoglobulin $\mathrm{M}(\mathrm{MD},-128.63 \mathrm{IU} / \mathrm{L} ; 95 \% \mathrm{CI},-151.55$ to $-105.71 ; P<0.00001$; Figure 11$)$.

The subgroup analyses, stratifying the trials according to the duration of treatment, did not reveal significant differences (Figure 11). There was high heterogeneity $\left(P<0.0001, R^{2}=91 \%\right)$, but the heterogeneity in each subgroup was acceptable, so we considered heterogeneity comes from the duration of treatment.

9. Triglycerides: four trials, which included 115 patients, reported data regarding this end point. ${ }^{13,14,17,18}$ Combination therapy significantly decreased the triglyceride levels compared with UDCA monotherapy (MD, $-26.84 \mathrm{mg} / \mathrm{dL}$; $95 \%$ CI, -36.51 to $-17.17 ; P<0.0001$; Figure 12$)$. Heterogeneity was absent $\left(P=0.54, I^{2}=0 \%\right)$.

10. Total cholesterol: four trials, which included 115 patients, reported data regarding this end point. ${ }^{13,14,17,18}$ Combination therapy significantly decreased the total cholesterol levels compared with UDCA monotherapy (MD, -21.58 $\mathrm{mg} / \mathrm{dL} ; 95 \% \mathrm{CI},-30.81$ to $-12.34 ; P<0.0001$; Figure 13 ). There was medium heterogeneity $\left(P=0.07, I^{2}=57 \%\right)$.

11. Serum bilirubin: four trials, which included 97 patients, reported data regarding this end point. ${ }^{13-15,18}$ Combination therapy decreased the serum bilirubin levels compared with UDCA monotherapy (MD, $-0.20 \mathrm{mg} / \mathrm{dL} ; 95 \%$

Table 2 Baseline characteristics of the trials included in the meta-analysis

\begin{tabular}{|c|c|c|c|c|c|c|c|}
\hline First author, year & $\begin{array}{l}\text { Mean age } \\
\text { (years) }\end{array}$ & $\begin{array}{l}\text { Monotherapy } \\
\text { (n) }\end{array}$ & $\begin{array}{l}\text { Combination } \\
\text { therapy (n) }\end{array}$ & $\begin{array}{l}\text { UDCA dose } \\
\text { (mg/day) }\end{array}$ & $\begin{array}{l}\text { Bezafibrate } \\
\text { dose (mg/day) }\end{array}$ & $\begin{array}{l}\text { Duration of } \\
\text { treatment } \\
\text { (months) }\end{array}$ & $\begin{array}{l}\text { Publication } \\
\text { type }\end{array}$ \\
\hline Nakai et al, ${ }^{20} 2000$ & 58 & 13 & 10 & 600 & 400 & 12 & Letter \\
\hline Kanda et al, ${ }^{19} 2003$ & 56 & II & II & 600 & 400 & 6 & Full text \\
\hline Itakura et al, ${ }^{18} 2004$ & 57 & 7 & 9 & 600 & 400 & 6 & Full text \\
\hline Iwasaki et al, ${ }^{13} 2008$ & 54 & 10 & 12 & 600 & 400 & 12 & Full text \\
\hline Hazzan and Tur-Kaspa, ${ }^{16}$ & 64 & 8 & 8 & $900-1,500$ & 400 & 24 & Full text \\
\hline \multicolumn{8}{|l|}{2010} \\
\hline Takeuchi et al, ${ }^{17} 201 \mathrm{I}$ & 57 & 22 & 15 & 600 & 400 & 24 & Full text \\
\hline Honda et al,"' 2013 & 58 & 31 & 19 & 600 & 400 & 3 & Full text \\
\hline Lens et al, ${ }^{14} 2014$ & 53 & 28 & 28 & $900-1,500$ & 400 & 3 & Full text \\
\hline Hosonuma et al, ${ }^{15} 2015$ & 64 & 14 & 13 & $600-900$ & 400 & 96 & Full text \\
\hline
\end{tabular}

Abbreviation: UDCA, ursodeoxycholic acid. 
Table 3 Meta-analysis of clinical events and biochemical parameter changes in the included studies

\begin{tabular}{|c|c|c|c|c|c|}
\hline Outcome title & $\begin{array}{l}\text { No of } \\
\text { studies }\end{array}$ & $\begin{array}{l}\text { No of } \\
\text { participants }\end{array}$ & Statistical method & Effect size & $P$-value \\
\hline Mortality & 9 & 269 & $\begin{array}{l}\text { Risk ratio } \\
(\mathrm{M}-\mathrm{H} \text {, fixed, } 95 \% \mathrm{Cl} \text { ) }\end{array}$ & $0.4 I(0.07,2.29)$ & 0.31 \\
\hline Pruritus & 4 & 131 & $\begin{array}{l}\text { Risk ratio } \\
(\mathrm{M}-\mathrm{H} \text {, fixed, } 95 \% \mathrm{Cl})\end{array}$ & $1.60(0.90,2.85)$ & 0.11 \\
\hline Adverse events & & & Risk ratio & & \\
\hline $\begin{array}{l}\text { I. Permanent discontinuation } \\
\text { of treatment }\end{array}$ & 2 & 83 & $(\mathrm{M}-\mathrm{H}$, fixed, $95 \% \mathrm{Cl})$ & $0.14(0.02,1.08)$ & 0.06 \\
\hline $\begin{array}{l}\text { 2. Not necessitating permanent } \\
\text { discontinuation of treatment }\end{array}$ & 9 & 269 & & $0.29(0.08,1.08)$ & 0.06 \\
\hline Mayo risk score & 2 & 60 & $\begin{array}{l}\text { Mean difference } \\
\text { (IV, fixed, } 95 \% \mathrm{Cl} \text { ) }\end{array}$ & $0.60(0.25,0.95)$ & 0.0008 \\
\hline Alkaline phosphatase & & & Mean difference & & \\
\hline I. Trial duration $\leq 24$ months & 6 & 171 & (IV, random, 95\% Cl) & $-255.57(-301.38,-209.77)$ & $<0.0001$ \\
\hline 2. Trial duration $>24$ months & 3 & 76 & & $-191.35(-263.62,-119.08)$ & $<0.0001$ \\
\hline Gamma-glutamyltransferase & & & Mean difference & & \\
\hline I. Change from baseline & 3 & 57 & (IV, fixed, 95\% Cl) & $-15.47(-32.11,1.18)$ & 0.07 \\
\hline 2. Final measurement values & 4 & 137 & & -66.4 I (-84.93, -47.88) & $<0.000 \mathrm{I}$ \\
\hline Alanine aminotransferase & & & Mean difference & & \\
\hline I. Trial duration $\leq 24$ months & 3 & 75 & (IV, fixed, 95\% Cl) & $-14.89(-21.07,-8.71)$ & $<0.0001$ \\
\hline 2. Trial duration $>24$ months & 1 & 37 & & $-9.40(-12.02,-6.78)$ & $<0.0001$ \\
\hline Immunoglobulin $M$ & & & Mean difference & & \\
\hline I. Trial duration $\leq 24$ months & 5 & 162 & (IV, fixed, 95\% Cl) & $-82.22(-108.76,-55.68)$ & $<0.0001$ \\
\hline 2. Trial duration $>24$ months & 1 & 37 & & $-264.70(-310.15,-219.25)$ & $<0.0001$ \\
\hline Triglycerides & 4 & 115 & $\begin{array}{l}\text { Mean difference } \\
\text { (IV, fixed, } 95 \% \mathrm{Cl} \text { ) }\end{array}$ & $-26.84(-36.5 I,-17.17)$ & $<0.0001$ \\
\hline Total cholesterol & 4 & 115 & $\begin{array}{l}\text { Mean difference } \\
\text { (IV, fixed, } 95 \% \mathrm{Cl} \text { ) }\end{array}$ & $-21.58(-30.81,-12.34)$ & $<0.0001$ \\
\hline Serum bilirubin & 4 & 97 & $\begin{array}{l}\text { Mean difference } \\
(\mathrm{IV}, \text { fixed, } 95 \% \mathrm{Cl})\end{array}$ & $-0.20(-0.33,-0.07)$ & 0.002 \\
\hline Albumin & 2 & 63 & $\begin{array}{l}\text { Mean difference } \\
\text { (IV, fixed, } 95 \% \mathrm{Cl} \text { ) }\end{array}$ & $-0.09(-0.27,0.10)$ & 0.35 \\
\hline AST & 2 & 39 & $\begin{array}{l}\text { Mean difference } \\
\text { (IV, fixed, } 95 \% \mathrm{Cl} \text { ) }\end{array}$ & $4.53(-2.54,11.60)$ & 0.21 \\
\hline
\end{tabular}

Abbreviations: AST, aspartate aminotransferase; $\mathrm{M}-\mathrm{H}$, Mantel-Haenszel; $\mathrm{Cl}$, confidence interval; IV, inverse-variance.

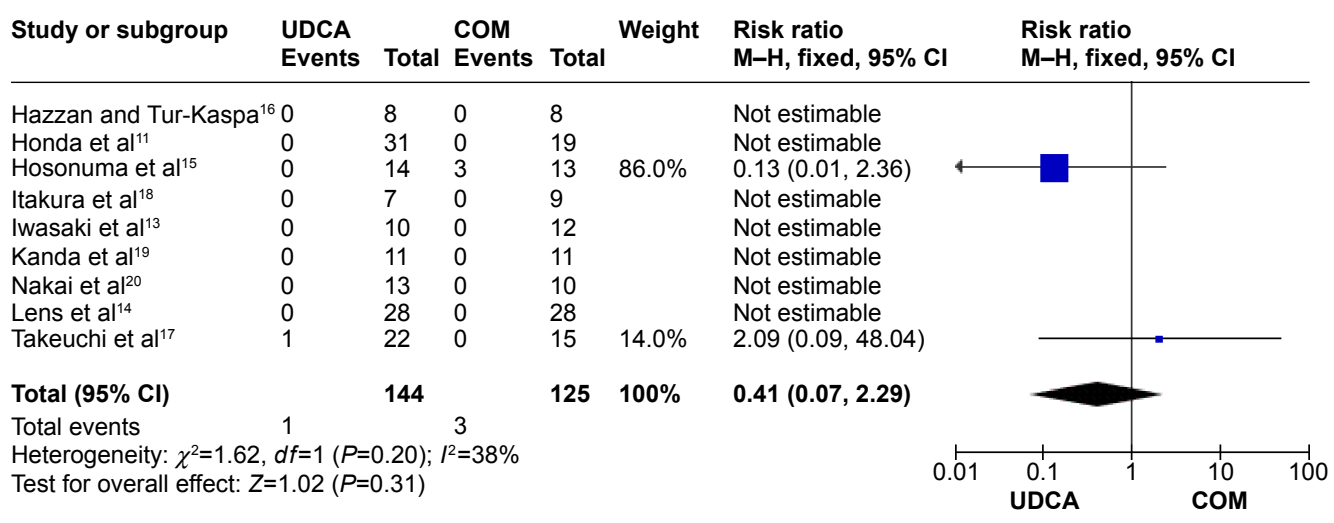

Figure 4 Mortality in primary biliary cirrhosis patients treated with monotherapy versus combination therapy.

Abbreviations: $\mathrm{Cl}$, confidence interval; COM, combination therapy; df, degrees of freedom; SD, standard deviation; M-H, Mantel-Haenszel; UDCA, ursodeoxycholic acid monotherapy. 


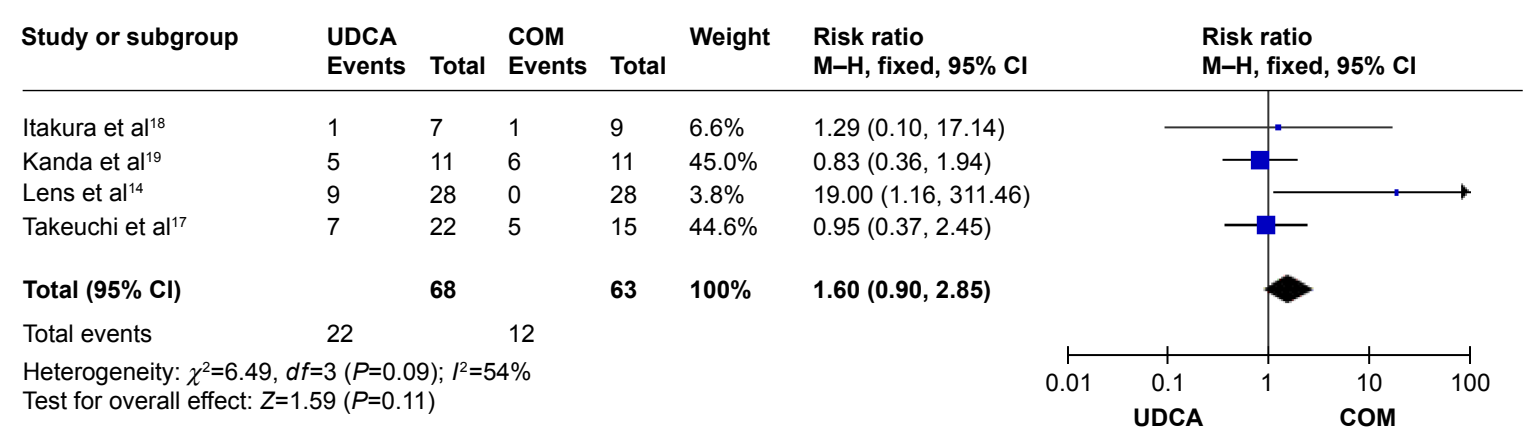

Figure 5 Effects of monotherapy versus combination therapy on pruritus in patients with primary biliary cirrhosis.

Abbreviations: $\mathrm{Cl}$, confidence interval; COM, combination therapy; df, degrees of freedom; M-H, Mantel-Haenszel; UDCA, ursodeoxycholic acid monotherapy.

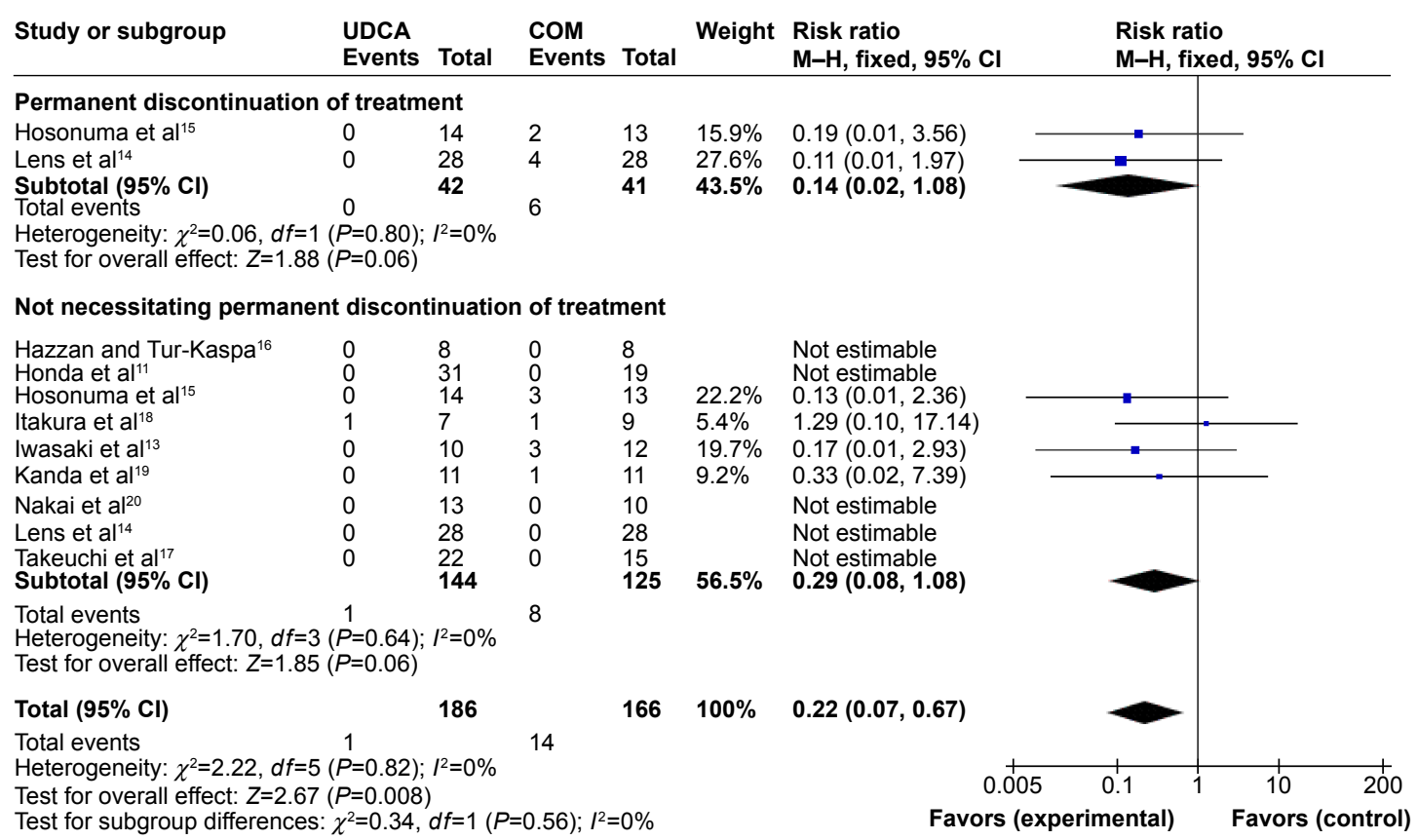

Figure 6 Adverse events in primary biliary cirrhosis patients treated with monotherapy versus combination therapy.

Abbreviations: $\mathrm{Cl}$, confidence interval; COM, combination therapy; df, degrees of freedom; SD, standard deviation; M-H, Mantel-Haenszel; UDCA, ursodeoxycholic acid monotherapy.

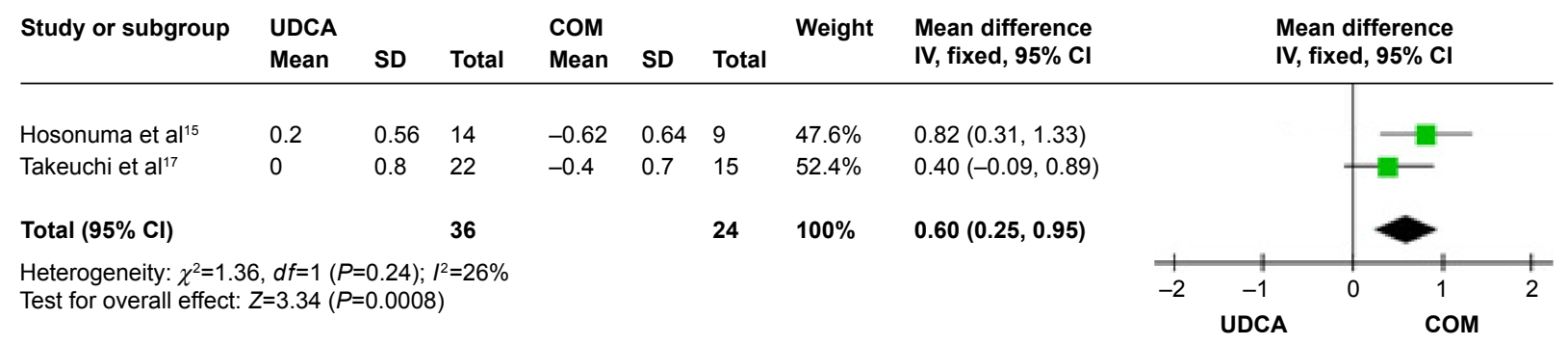

Figure 7 Mayo risk score in primary biliary cirrhosis patients treated with monotherapy versus combination therapy.

Abbreviations: $\mathrm{Cl}$, confidence interval; COM, combination therapy; df, degrees of freedom; SD, standard deviation; UDCA, ursodeoxycholic acid monotherapy; IV, inversevariance. 


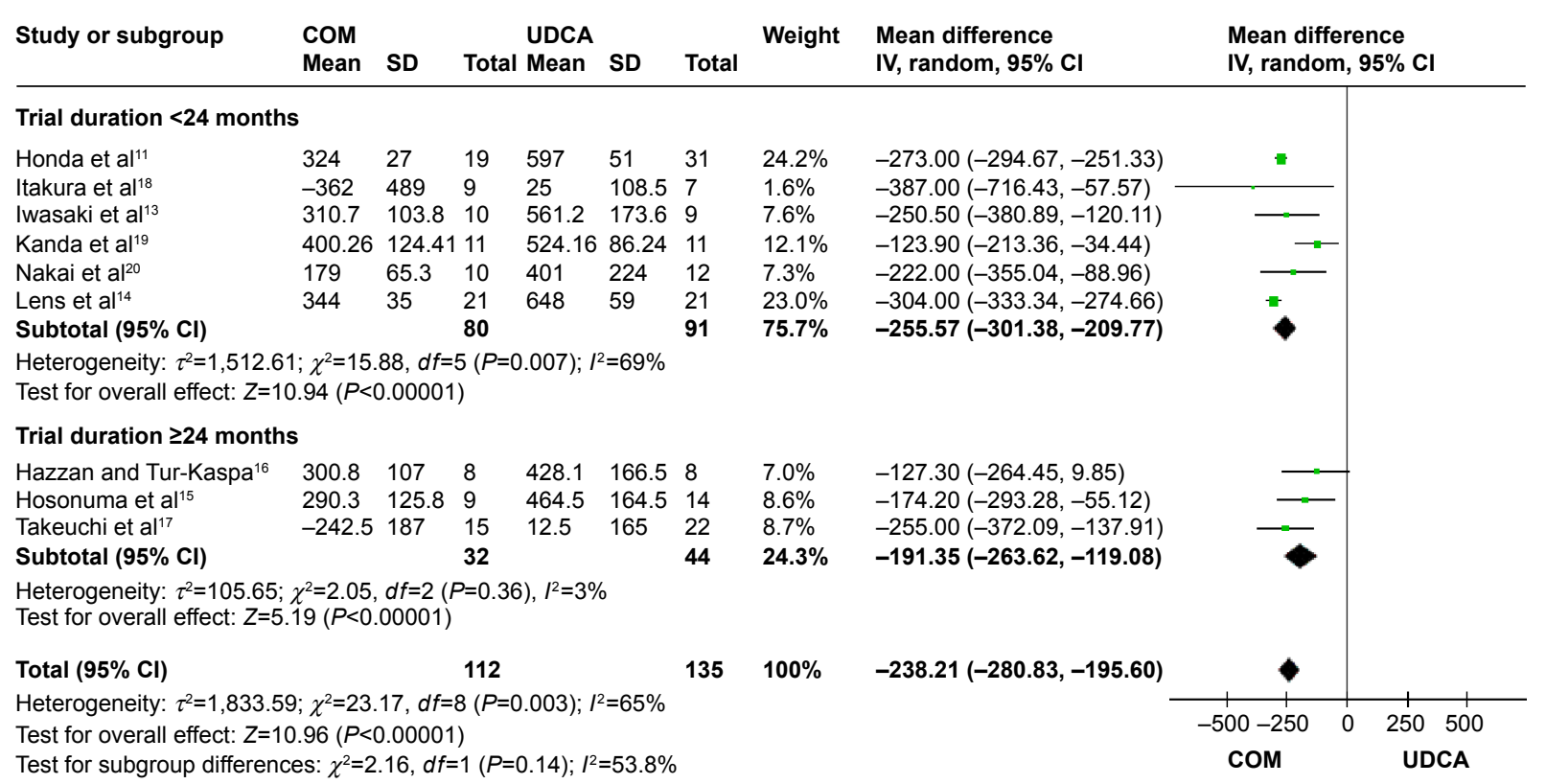

Figure 8 Alkaline phosphatase levels in primary biliary cirrhosis patients treated with monotherapy versus combination therapy.

Abbreviations: $\mathrm{Cl}$, confidence interval; COM, combination therapy; df, degrees of freedom; SD, standard deviation; UDCA, ursodeoxycholic acid monotherapy; IV, inversevariance.

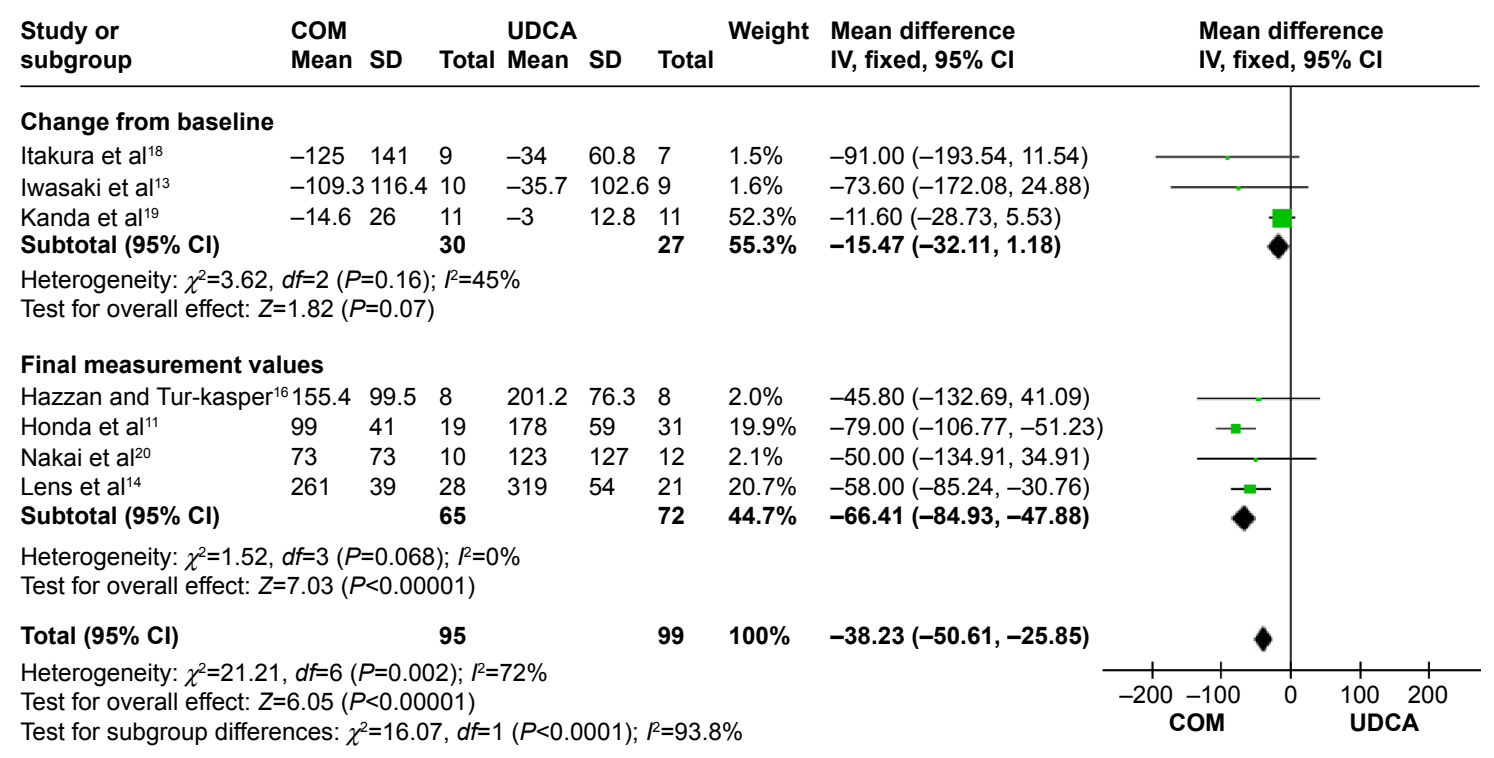

Figure 9 Gamma-glutamyltransferase levels in primary biliary cirrhosis patients treated with monotherapy versus combination therapy.

Abbreviations: Cl, confidence interval; COM, combination therapy; df, degrees of freedom; SD, standard deviation; UDCA, ursodeoxycholic acid monotherapy; IV, inversevariance.

CI, -0.33 to $-0.07 ; P=0.002$; Figure 14$)$. Heterogeneity was absent $\left(P=1, I^{2}=0 \%\right)$.

12. Albumin: two trials, which included 63 patients, reported data regarding this end point. ${ }^{14,15}$ There was medium heterogeneity $\left(P=0.15, I^{2}=51 \%\right)$ and there were no significant differences between the two groups (MD, $-0.09 \mathrm{mg} / \mathrm{dL}$; $95 \% \mathrm{CI},-0.21$ to $-0.10 ; P=0.35$; Figure 15$)$.

13. Aspartate aminotransferase (AST): two trials, which included 39 patients, reported data regarding this end point. ${ }^{15,18}$ Heterogeneity was absent $\left(P=0.38, I^{2}=0 \%\right)$ and there were no significant differences between the two groups (MD, $4.53 \mathrm{mg} / \mathrm{dL} ; 95 \% \mathrm{CI},-2.54$ to 11.60 ; $P=0.21$; Figure 16).

\section{Discussion}

Evidence shows that the combination therapy of UDCA and bezafibrate significantly improved liver function early in 1 month. ${ }^{21}$ Combination therapy reduced the serum levels 


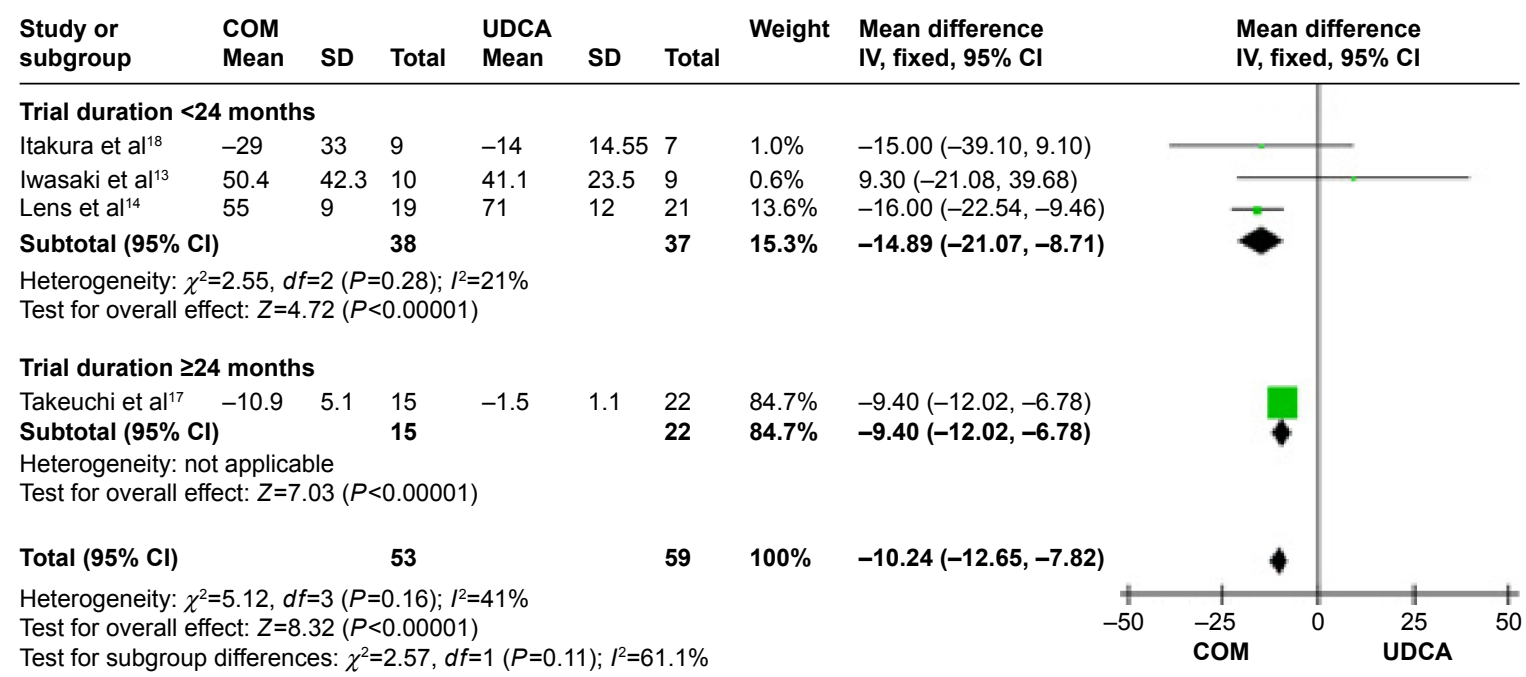

Figure 10 Alanine aminotransferase levels in primary biliary cirrhosis patients treated with monotherapy versus combination therapy.

Abbreviations: $\mathrm{Cl}$, confidence interval; COM, combination therapy; df, degrees of freedom; SD, standard deviation; UDCA, ursodeoxycholic acid monotherapy; IV, inversevariance.

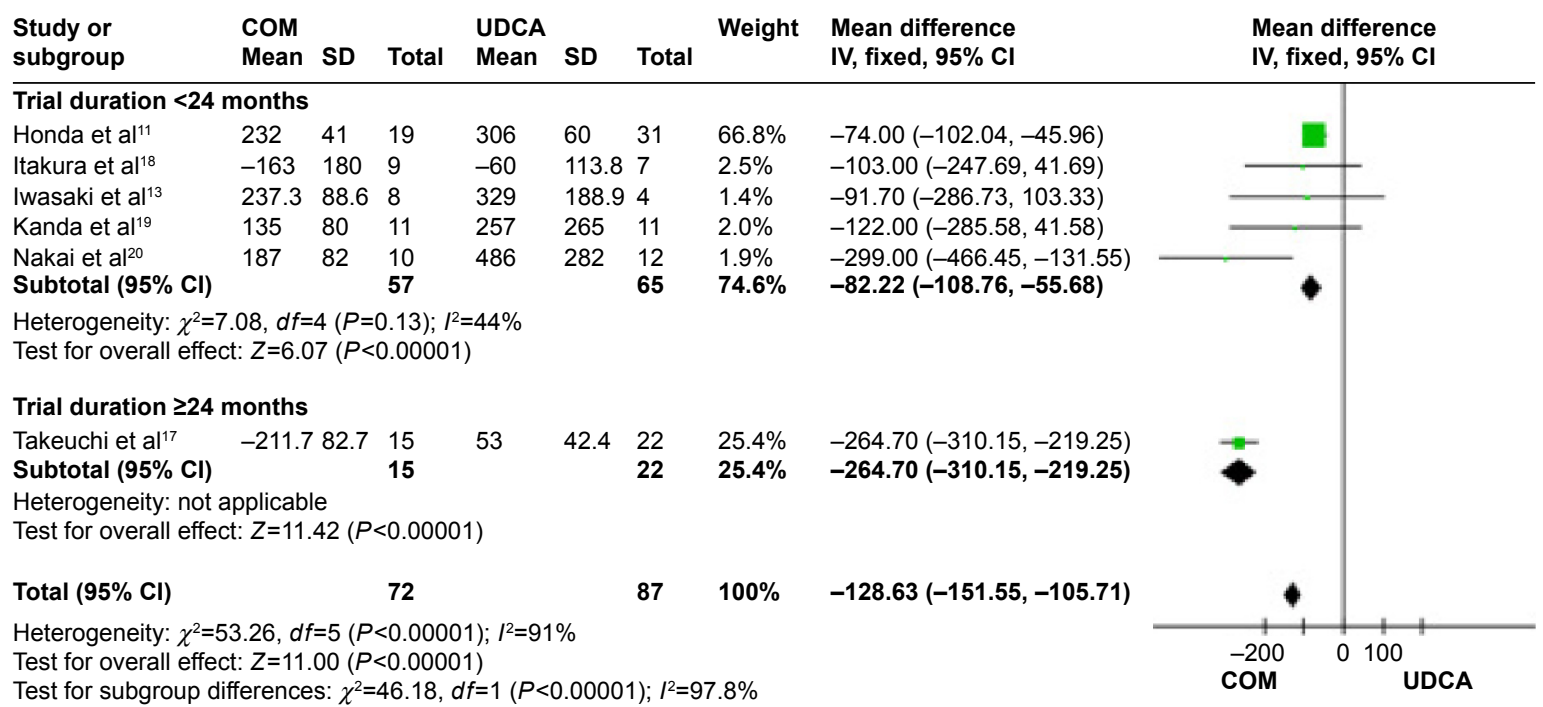

Figure I I Immunoglobulin M levels in primary biliary cirrhosis patients treated with monotherapy versus combination therapy.

Abbreviations: $\mathrm{Cl}$, confidence interval; COM, combination therapy; df, degrees of freedom; SD, standard deviation; UDCA, ursodeoxycholic acid monotherapy; IV, inversevariance.

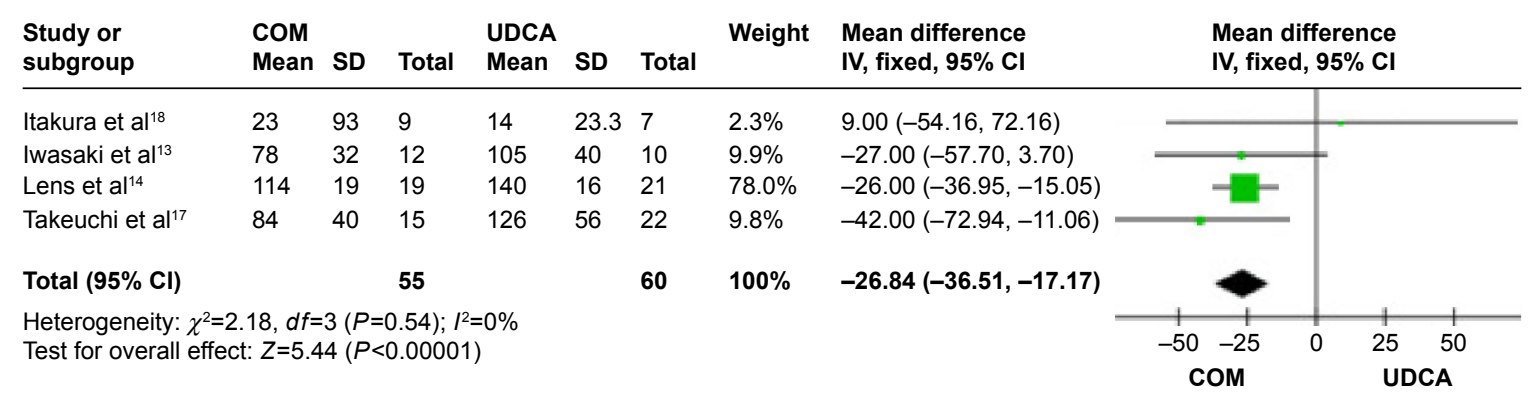

Figure 12 Triglycerides levels in primary biliary cirrhosis patients treated with monotherapy versus combination therapy.

Abbreviations: $\mathrm{Cl}$, confidence interval; COM, combination therapy; df, degrees of freedom; SD, standard deviation; UDCA, ursodeoxycholic acid monotherapy; IV, inversevariance. 


\begin{tabular}{|c|c|c|c|c|c|c|c|c|c|c|c|}
\hline $\begin{array}{l}\text { Study or } \\
\text { subgroup }\end{array}$ & $\begin{array}{l}\text { COM } \\
\text { Mean }\end{array}$ & SD & Total & $\begin{array}{l}\text { UDCA } \\
\text { Mean }\end{array}$ & SD & Total & Weight & $\begin{array}{l}\text { Mean difference } \\
\text { IV, fixed, } 95 \% \mathrm{CI}\end{array}$ & $\begin{array}{l}\text { Mean d } \\
\text { IV, fixec }\end{array}$ & $\begin{array}{l}\text { lifference } \\
\text { d, } 95 \% \mathrm{Cl}\end{array}$ & \\
\hline Itakura et al ${ }^{18}$ & 26 & 60 & 9 & -4 & 16.4 & 7 & $5.1 \%$ & $30.00(-11.04,71.04)$ & & & \\
\hline Iwasaki et al ${ }^{13}$ & 199 & 27 & 12 & 225 & 28 & 10 & $15.9 \%$ & $-26.00(-49.12,-2.88)$ & & & \\
\hline Lens et $\mathrm{al}^{14}$ & 263 & 19 & 19 & 289 & 19 & 21 & $61.3 \%$ & $-26.00(-37.79,-14.21)$ & & & \\
\hline Takeuchi et al ${ }^{17}$ & 190 & 30 & 15 & 207 & 38 & 22 & $17.7 \%$ & $-17.00(-38.97,4.97)$ & & & \\
\hline Total $(95 \% \mathrm{Cl})$ & & & 55 & & & 60 & $100 \%$ & $-21.58(-30.81,-12.34)$ & & & \\
\hline \multicolumn{8}{|c|}{$\begin{array}{l}\text { Heterogeneity: } \chi^{2}=6.92, d f=3(P=0.07) ; I^{2}=57 \% \\
\text { Test for overall effect: } Z=4.58(P<0.00001)\end{array}$} & -100 & $\begin{array}{l}-50 \\
\text { Favors } \\
\text { xperimental) }\end{array}$ & $\begin{array}{c}50 \\
\text { Favors } \\
\text { (control) }\end{array}$ & 100 \\
\hline
\end{tabular}

Figure 13 Total cholesterol levels in primary biliary cirrhosis patients treated with monotherapy versus combination therapy.

Abbreviations: $\mathrm{Cl}$, confidence interval; COM, combination therapy; df, degrees of freedom; SD, standard deviation; UDCA, ursodeoxycholic acid monotherapy; IV, inversevariance.

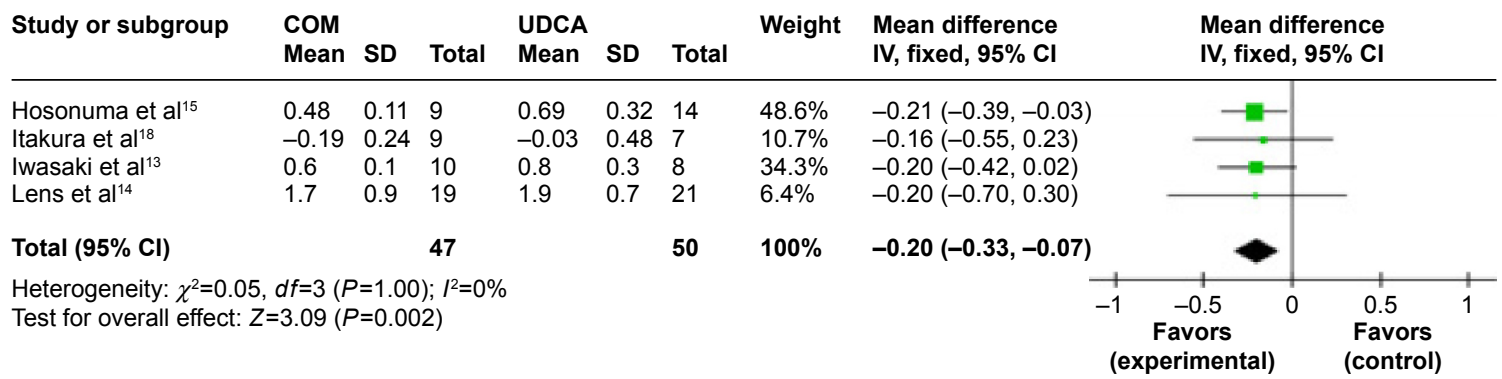

Figure 14 Serum bilirubin levels in primary biliary cirrhosis patients treated with monotherapy versus combination therapy.

Abbreviations: $\mathrm{Cl}$, confidence interval; COM, combination therapy; df, degrees of freedom; SD, standard deviation; UDCA, ursodeoxycholic acid monotherapy; IV, inversevariance.

\begin{tabular}{|c|c|c|c|c|c|c|c|c|c|}
\hline Study or subgroup & $\begin{array}{l}\text { COM } \\
\text { Mean }\end{array}$ & SD & Total & $\begin{array}{l}\text { UDCA } \\
\text { Mean }\end{array}$ & SD & Total & Weight & $\begin{array}{l}\text { Mean difference } \\
\text { IV, fixed, } 95 \% \mathrm{CI}\end{array}$ & $\begin{array}{l}\text { Mean difference } \\
\text { IV, fixed, } 95 \% \mathrm{CI}\end{array}$ \\
\hline Hosonuma et al ${ }^{15}$ & 41.5 & 0.6 & 19 & 41.8 & 0.5 & 21 & $29.4 \%$ & $-0.30(-0.64,0.04)$ & \\
\hline Lens et $\mathrm{al}^{14}$ & 4 & 0.3 & 9 & 4 & 0.2 & 14 & $70.6 \%$ & $0.00(-0.22,0.22)$ & \\
\hline Total $(95 \% \mathrm{Cl})$ & & & 28 & & & 35 & $100 \%$ & $-0.09(-0.27,0.10)$ & \\
\hline \multicolumn{9}{|c|}{$\begin{array}{l}\text { Heterogeneity: } \chi^{2}=2.06, d f=1(P=0.15) ; I^{2}=51 \% \\
\text { Test for overall effect: } Z=0.93(P=0.35)\end{array}$} & $\begin{array}{cccc}\begin{array}{c}-1-0.5 \\
\text { Favors }\end{array} & 0 & 0.5 & 1 \\
\text { (experimental) } & & \begin{array}{c}\text { Favors } \\
\text { (control) }\end{array}\end{array}$ \\
\hline
\end{tabular}

Figure 15 Albumin levels in primary biliary cirrhosis patients treated with monotherapy versus combination therapy.

Abbreviations: $\mathrm{Cl}$, confidence interval; COM, combination therapy; df, degrees of freedom; SD, standard deviation; UDCA, ursodeoxycholic acid monotherapy; IV, inversevariance.

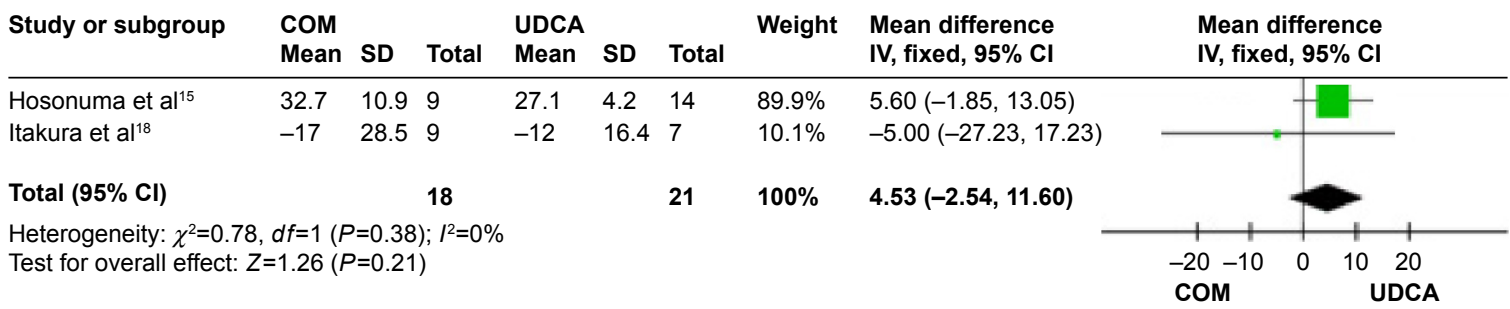

Figure 16 AST levels in primary biliary cirrhosis patients treated with monotherapy versus combination therapy.

Abbreviations: AST, aspartate aminotransferase; $\mathrm{Cl}$, confidence interval; COM, combination therapy; df, degrees of freedom; SD, standard deviation; UDCA, ursodeoxycholic acid monotherapy; IV, inverse-variance. 
of gamma-glutamyltransferase, ALP, and immunoglobulin $\mathrm{M}$, but there were no significant differences in the incidence of all-cause mortality, adverse events, and pruritus. ${ }^{12,22}$ However, none of the studies elucidated the long-term prognosis, efficacy, and safety of combination therapy. Most recently, Hosonuma et al reported that long-term combination therapy showed significant improvements in the serum ALP levels and Mayo risk score, but may cause notable adverse events such as renal dysfunction and increased serum creatinine levels. ${ }^{15}$ We therefore undertook this meta-analysis and paid special attention to the adverse events.

We did not find statistically significant effects of bezafibrate on mortality or pruritus, but combination therapy with UDCA could improve liver biochemistry indicators such as ALP, gamma-glutamyltransferase, immunoglobulin $\mathrm{M}$, total cholesterol, bilirubin, ALT, and triglycerides in PBC patients. The Mayo risk score, used as an indicator of the severity of $\mathrm{PBC}$, in the combination therapy group was significantly lower than that in the UDCA monotherapy group. We did not have enough data to record changes in the histological parameters. Only one case report, including three patients, observed improvements in the histopathological condition after the use of bezafibrate. ${ }^{23}$ Further studies are required to evaluate whether this combination therapy improves the histological staging and prognosis. We performed subgroup analyses, in which trials were grouped according to duration of treatment, but there were no significant differences in liver biochemistry indicators.

$\mathrm{PBC}$ is an autoimmune disease characterized by chronic progressive destruction of small intrahepatic bile ducts with portal inflammation, which ultimately leads to fibrosis. ${ }^{24,25}$ It has been proposed that bezafibrate plays a therapeutic role by downregulation of nitrite production by dendritic cells. ${ }^{21}$ One study evaluated changes in the serum cytokine levels in response to treatment to identify the cytokines that reflect improved clinical results. Serum interleukin-18 (IL-18) levels in the groups at two time points were measured before (baseline) assignment of either treatment and after 12 months of the assigned treatment, but no significant difference was observed between the two groups. ${ }^{15}$

Adverse events in the combination therapy group were more frequent than in the monotherapy group. Most of the adverse events were myalgia, polydipsia, aggravated pruritus, arthritis, leg edema, and gastrointestinal discomfort such as nausea or heartburn. Two studies mentioned a self-limited serum creatine phosphokinase elevation in patients who received bezafribrate. ${ }^{13,15}$ During long-term administration of the combination therapy, bezafibrate treatment was discontinued in two cases due to a gradual elevation of the serum creatinine levels shortly after the initiation of bezafibrate treatment. ${ }^{15}$ Close attention should be paid to adverse events during long-term combination therapy.

To complete the results, we also covered some nonrandomized studies and conference reports. A retrospective study including 1,121 PBC patients suggested that normalization of ALT levels with additional bezafibrate treatment significantly decreased the rate of occurrence of liver-related symptoms in asymptomatic PBC patients with suboptimal responses to UDCA. ${ }^{24} \mathrm{We}$ found one related conference report that stated that higher ALT and ALP levels at diagnosis and sustained high levels of ALT are predictors for poor prognosis in PBC. ${ }^{25} \mathrm{We}$ infer that ALT may play an important role in the progression of PBC. ${ }^{26,27}$

\section{Limitations}

There are some limitations of this study. Firstly, although we included nine studies in this analysis, the sample size was small and only one long-term combination therapy study was included. Subgroup analyses according to duration of treatment failed to identify significant differences. More long-term clinical studies on the combination therapy of bezafibrate and UDCA may be needed. Secondly, of the nine trials, all were assessed as having a high risk of bias. ${ }^{28}$ Finally, there were insufficient data to record changes in the histological parameters and quality of life; there were only two studies that reported the Mayo risk score, and the smaller trials were less statistically significant. We suggest that a pathogenesis of PBC should be established and improved in the near future, including inflammation of the liver, ${ }^{29,30}$ apoptosis and autophagy, ${ }^{31-33}$ the molecular mechanisms of injury and repair, ${ }^{34,35}$ inflammation and fibrosis, ${ }^{36}$ inflammation and cancer, ${ }^{37-39}$ and other important signaling pathways and related targets; therefore, early treatment can effectively achieve or delay the progression of liver disease. We also should pay attention to the evidence-based medical research of PBC.

\section{Conclusion}

Significant improvements in the Mayo risk score and liver biochemistry indicators, such as ALP, gamma-glutamyltransferase, immunoglobulin $\mathrm{M}$, total cholesterol, bilirubin, ALT, and triglycerides, compared with UDCA monotherapy suggest that combination therapy is more favorable, although the survival rate was not significantly different between the groups. However, close attention should be paid to adverse events during long-term combination therapy. Larger, 
controlled multicenter studies are required to evaluate whether this combination therapy improves the occurrence of adverse events, histological staging, quality of life, and prognosis. We also suggest that an animal model of autoimmune liver disease should be established to facilitate research into the pathogenesis of PBC and target therapies. ${ }^{40-42}$

\section{Acknowledgments}

This study was supported by the National Natural Science Foundation of China (grant number: 81270515), the Chinese Foundation for Hepatitis Prevention and Control (grant numbers: WBN20100021 and CFHPC20131011), and the Shanghai Municipal Health Bureau Foundation (grant numbers: 2011287 and 2012107).

\section{Author contributions}

All the authors conceived the study, performed the literature search, quality assessment, and performed the statistical analysis. All the authors were involved in manuscript writing and preparation. All the authors have read and approved of the final manuscript.

\section{Disclosure}

The authors report no conflicts of interest in this work.

\section{References}

1. Prince MI, James OF. The epidemiology of primary biliary cirrhosis. Clin Liver Dis. 2003;7:795-819.

2. Rudic JS, Poropat G, Krstic MN, et al. Ursodeoxycholic acid for primary biliary cirrhosis (Review). Cochrane Database Syst Rev. 2012;12:CD000551.

3. Gong Y, Klingenberg SL, Gluud C. Systematic review and metaanalysis: D-Penicillamine vs placebo/no intervention in patients with primary biliary cirrhosis - Cochrane Hepato-Biliary Group. Aliment Pharmacol Ther. 2006;24(11-12):1535-1544.

4. Giljaca V, Poropat G, Stimac D, Gluud C. Methotrexate for primary biliary cirrhosis. Cochrane Database Syst Rev. 2010;(5):CD004385.

5. Gong Y, Gluud C. Colchicine for primary biliary cirrhosis: a Cochrane Hepato-Biliary Group systematic review of randomized clinical trials. Am J Gastroenterol. 2005;100(8):1876-1885.

6. Gong Y, Christensen E, Gluud C. Azathioprine for primary biliary cirrhosis. Cochrane Database Syst Rev. 2007;(3):CD006000.

7. Gong Y, Christensen E, Gluud C. Cyclosporin A for primary biliary cirrhosis. Cochrane Database Syst Rev. 2007;(3):CD005526.

8. Zhang Y, Lu J, Dai W, et al. Combination therapy of ursodeoxycholic acid and corticosteroids for primary biliary cirrhosis with features of autoimmune hepatitis: a meta-analysis. Gastroenterol Res Pract. 2013;2013:490731. doi:10.1155/2013/490731.

9. Zhang H, Yang J, Zhu R, et al. Combination therapy of ursodeoxycholic acid and budesonide for PBC-AIH overlap syndrome: a meta-analysis. Drug Des Devel Ther. 2015;9:567-574.

10. Zhang Y, Li S, He L, et al. Combination therapy of fenofibrate and ursodeoxycholic acid in patients with primary biliary cirrhosis who respond incompletely to UDCA monotherapy: a meta-analysis. Drug Des Devel Ther. 2015;9:2757-2566.
11. Honda A, Ikegami T, Nakamuta M, et al. Anticholestatic effects of bezafibrate in patients with primary biliary cirrhosis treated with ursodeoxycholic acid. Hepatology. 2013;57(5):1931.

12. Zhang Y, Chen K, Dai W, et al. Combination therapy of bezafibrate and ursodeoxycholic acid for primary biliary cirrhosis: a meta-analysis. Hepatol Res. 2015;45(1):48-58. doi:10.1111/hepr.12373. Epub 2014 Jul 28.

13. Iwasaki $\mathrm{S}$, Ohira $\mathrm{H}$, Nishiguchi $\mathrm{S}$, et al. The efficacy of ursodeoxycholic acid and bezafibrate combination therapy for primary biliary cirrhosis: a prospective, multicenter study. Hepatol Res. 2008;38(6):557.

14. Lens S, Leoz M, Nazal L, et al. Bezafibrate normalizes alkaline phosphatase in primary biliary cirrhosis patients with incomplete response to ursodeoxycholic acid. Liver Int. 2014;34(2):197-203. doi:10.1111/ liv.12290. Epub 2013 Sep 2.

15. Hosonuma K, Sato K, Yamazaki Y, et al. A prospective randomized controlled study of long-term combination therapy using ursodeoxycholic acid and bezafibrate in patients with primary biliary cirrhosis and dyslipidemia. Am J Gastroenterol. 2015;110(3):423-431. doi:10.1038/ ajg.2015.20. Epub 2015 Mar 3.

16. Hazzan R, Tur-Kaspa R. Bezafibrate treatment of primary biliary cirrhosis following incomplete response to ursodeoxycholic acid. $J$ Clin Gastroenterol. 2010;44(5):371.

17. Takeuchi Y, Ikeda F, Fujioka S, et al. Additive improvement induced by bezafibrate in patients with primary biliary cirrhosis showing refractory response to ursodeoxycholic acid. J Gastroenterol Hepatol. 2011;26(9):1395-1401. doi:10.1111/j.1440-1746.2011.06737.x.

18. Itakura J, Izumi N, Nishimura $Y$, et al. Prospective randomized crossover trial of combination therapy with bezafibrate and UDCA for primary biliary cirrhosis. Hepatol Res. 2004;29(4):216-222.

19. Kanda T, Yokosuka O, Imazeki F, Saisho H. Bezafibrate treatment: a new medical approach for PBC patients. J Gastroenterol. 2003; 38(6):573-578.

20. Nakai S, Masaki T, Kurokohchi K, Deguchi A, Nishioka M. Combination therapy of bezafibrate and ursodeoxycholic acid in primary biliary cirrhosis: a preliminary study. Am J Gastroenterol. 2000;95(1):326.

21. Akbar SM, Furukawa S, Nakanishi S, et al Therapeutic efficacy of decreased nitrite production by bezafibrate in patients with primary biliary cirrhosis. J Gastroenterol. 2005;40(2):157-163.

22. Rudic JS, Poropat G, Krstic MN, Bjelakovic G, Gluud C. Bezafibrate for primary biliary cirrhosis. Cochrane Database Syst Rev. 2012;1:CD009145. doi:10.1002/14651858.CD009145.pub2.

23. Kurihara T, Maeda A, Shigemoto M, et al. Investigation into the efficacy of bezafibrate against primary biliary cirrhosis, with histological references from cases receiving long term monotherapy. Am J Gastroenterol. 2002;97(1):212-214

24. Gershwin ME, Ansari AA, Mackay IR, et al. Primary biliary cirrhosis: an orchestrated immune response against epithelial cells. Immunol Rev. 2000;174:210-225.

25. Palmer JM, Kirby JA, Jones DE. The immunology of primary biliary cirrhosis: the end of the beginning? Clin Exp Immunol. 2002;129:191-197.

26. Tanaka A, Hirohara J, Nakanuma Y, et al. Biochemical responses to bezafibrate improve long-term outcome in asymptomatic patients with primary biliary cirrhosis refractory to UDCA. J Gastroenterol. 2015;50(6):675-682. doi:10.1007/s00535-014-0998-z. Epub 2014 Sep 20.

27. Takano K, Saeki C, Nakagawa R, et al. Long term prognosis and clinical features in patients with primary biliary cirrhosis. Hepatol Int. 2011; 5(2):607-624. doi:10.1007/s12072-015-9609-1.

28. Schulz KF, Chalmers L, Hayes RJ, Altman DG. Empirical evidence of bias: dimensions of methodological quality associated with estimates of treatment effects in controlled trials. $J$ Am Med Assoc. 1995; 273(5):408-412.

29. Chen K, Li J, Wang J, et al. 15-Deoxy- $\gamma 12$, 14-prostaglandin J2 reduces liver impairment in a model of ConA-induced acute hepatic inflammation by activation of PPAR $\gamma$ and reduction in NF- $\mathrm{KB}$ Activity. PPAR Res. 2014;2014:215631. 
30. Cheng P, Chen K, Xia Y, et al. Hydrogen sulfide, a potential novel drug, attenuates concanavalin A-induced hepatitis. Drug Des Devel Ther. 2014;8:1277-1286. doi:10.2147/DDDT.S66573.

31. Shen M, Lu J, Dai W, et al. Ethyl pyruvate ameliorates hepatic ischemia-reperfusion injury by inhibiting intrinsic pathway of apoptosis and autophagy. Mediators Inflamm. 2013;2013:461536. doi:10.1155/2013/461536. Epub 2013 Dec 25.

32. Cheng $\mathrm{P}$, Wang $\mathrm{F}$, Chen $\mathrm{K}$, et al. Hydrogen sulfide ameliorates ischemia/reperfusion-induced hepatitis by inhibiting apoptosis and autophagy pathways. Mediators Inflamm. 2014;2014:935251. doi:10.1155/2014/935251. Epub 2014 May 21.

33. Wang C, Chen K, Xia Y, et al. N-Acetylcysteine attenuates ischemiareperfusion-induced apoptosis and autophagy in mouse liver via regulation of the ROS/JNK/Bcl-2 pathway. PLoS One. 2014;9(9):e108855. doi:10.1371/journal.pone.0108855.

34. Wang C, Xia Y, Zheng Y, et al. Protective effects of N-acetylcysteine in concanavalin A induced hepatitis in mice, induced hepatitis in mice. Mediators Inflamm. 2015;2015:189785.

35. Li J, Wang F, Xia Y, et al. Astaxanthin pretreatment attenuates hepatic ischemia reperfusion-induced apoptosis and autophagy via the ROS/ MAPK pathway in mice. Marine Drugs. 2015;13(6):3368-3387.

36. Shen M, Chen K, Lu J, et al. Protective effect of astaxanthin on liver fibrosis through modulation of TGF-ß1 expression and autophagy. Mediators Inflamm. 2014;2014:954502. doi:10.1155/2014/954502. Epub 2014 Apr 17.
37. Dai W, Wang F, He L, et al. Genistein inhibits hepatocellular carcinoma cell migration by reversing the epithelial-mesenchymal transition: partial mediation by the transcription factor NFAT1. Mol Carcinog. 2015;54(4):301-311.

38. Dai W, Wang F, Lu J, et al. By reducing hexokinase 2, resveratrol induces apoptosis in HCC cells addicted to aerobic glycolysis and inhibits tumor growth in mice. Oncotarget. 2015;6(15):13703-13717.

39. Jie L, Fan W, Weiqi D, et al. The hippo-yes association protein pathway in liver cancer. Gastroenterol Res Pract. 2013;2013:187070. doi:10.1155/2013/187070. Epub 2013 Aug 6.

40. Zhou Y, Dai W, Lin C, et al. Protective effects of necrostatin-1 in concanavalin A-induced acute hepatic injury in mice. Mediators Inflamm. 2013;2013:706156. doi:10.1155/2013/706156. Epub 2013 Oct 1.

41. Shen M, Lu J, Cheng P, et al. Ethyl pyruvate pretreatment attenuates concanavalin A-induced autoimmune hepatitis in mice. PLoS One. 2014;9(2):e87977. doi:10.1371/journal.pone.0087977.

42. Zhou Y, Chen K, He L, et al. The protective effect of resveratrol on concanavalin-A-induced acute hepatic injury in mice. Gastroenterol Res Pract. 2015;(2015):506390.
Drug Design, Development and Therapy

\section{Publish your work in this journal}

Drug Design, Development and Therapy is an international, peerreviewed open-access journal that spans the spectrum of drug design and development through to clinical applications. Clinical outcomes, patient safety, and programs for the development and effective, safe, and sustained use of medicines are a feature of the journal, which

\section{Dovepress}

has also been accepted for indexing on PubMed Central. The manuscript management system is completely online and includes a very quick and fair peer-review system, which is all easy to use. Visit http://www.dovepress.com/testimonials.php to read real quotes from published authors.

Submit your manuscript here: http://www.dovepress.com/drug-design-development-and-therapy-journal 